\title{
Glass Ionomer Sealants Can Prevent Dental Caries but Cannot Prevent Posteruptive Breakdown on Molars Affected by Molar Incisor Hypomineralization: One-Year Results of a Randomized Clinical Trial
}

\author{
Milou S. Schraverus ${ }^{a}$ Isabel C. Olegário ${ }^{b}$ Clarissa C. Bonifácio $^{a}$ \\ Ana Paola R. González ${ }^{c}$ Murisi Pedroza ${ }^{c}$ Daniela Hesse ${ }^{a}$ \\ ${ }^{a}$ Department of Paediatric Dentistry, Academic Centre for Dentistry Amsterdam (ACTA), Amsterdam, The \\ Netherlands; ${ }^{b}$ Department of Public and Child Dental Health, Dublin Dental University Hospital, Trinity College, \\ Dublin, Ireland; ' Programme of Specialization in Paediatric Dentistry, Dental School, Los Altos Campus, University of \\ Guadalajara, Guadalajara, Mexico
}

\section{Keywords}

Glass ionomer cement - Molar incisor hypomineralization .

Dental caries · Posteruptive breakdown

\begin{abstract}
To evaluate the preventive effect of glass ionomer cement (GIC) against dental caries and posteruptive breakdown (PEB) on molars affected by molar incisor hypomineralization $(\mathrm{MIH})$. In this randomized clinical trial, 77 children aged 5-9 years with at least $1 \mathrm{MIH}$-affected molar and without PEB or dentin caries lesions $(n=228)$ were included and randomly allocated to one of the following groups: (1) MIH-affected molars that remained unsealed and (2) MIH-affected molars that received GIC sealants. Dental caries and PEB were clinically evaluated after 6 and 12 months. Associations between dental caries and PEB with independent variables were evaluated using logistic regression analysis $(p<0.05)$. The MIHaffected molars allocated to the GIC sealant group were less likely to develop dental caries compared to those allocated to the unsealed group ( $\mathrm{OR}=0.23 ; 95 \% \mathrm{Cl} 0.06-0.95)$. Conversely, application of a $\mathrm{GIC}$ sealant was not associated with prevention of PEB $(p=0.313)$. Furthermore, MIH-affected
\end{abstract}

karger@karger.com www.karger.com/cre

Karger $\stackrel{\text { ' }}{5}$

BOPEN ACCESS
(C) 2021 The Author(s)

Published by S. Karger AG, Basel

This is an Open Access article licensed under the Creative Commons Attribution-NonCommercial-4.0 International License (CC BY-NC) (http://www.karger.com/Services/OpenAccessLicense), applicable to the online version of the article only. Usage and distribution for commercial purposes requires written permission. molars presenting yellow-brown opacities were almost 5 times more likely to develop dental caries $(p=0.013)$ and PEB $(p=0.001)$ compared to those presenting white-creamy opacities. We can conclude that GIC sealants can prevent dental caries on $\mathrm{MIH}$-affected molars; however, the same protective effect was not observed for PEB.

(C) 2021 The Author(s)

Published by S. Karger AG, Basel

\section{Introduction}

Molar incisor hypomineralization $(\mathrm{MIH})$ is a qualitative dental enamel defect with different degrees of severity [Weerheijm et al., 2001]. This defect affects at least 1 out of 4 first permanent molars and is frequently associated with affected permanent incisors. The prevalence of MIH has been reported in several countries and the mean global prevalence is estimated to be between 13.1 [Schwendicke et al., 2018] and 14.2\% [Zhao et al., 2018], with no difference between males and females [Dave and Taylor, 2018]. In Mexico, the country where this investigation was carried out, a prevalence of $15.8 \%$ has been reported among schoolchildren [Gurrusquieta et al., 2017]. 
MIH-affected teeth are characterized by demarcated opacities (white-creamy and yellow-brown) that may possess decreased hardness and increased roughness compared to normal enamel [Weerheijm et al., 2001; Weerheijm, 2003; Fagrell et al., 2010]. As a result, MIH molars may be more prone to enamel and dentin breakdown and to the development of atypical caries lesions [Farah et al., 2010]. Furthermore, patients with MIH often report hypersensitivity from affected teeth [Weerheijm et al., 2001]. This may hinder proper oral hygiene measures on surfaces that are already prone to plaque accumulation due to roughness. Combined, these factors are influential in the development of posteruptive breakdown (PEB) and rapid caries development [Weerheijm et al., 2001; Weerheijm, 2003; Fagrell et al., 2010], ultimately leading to an increased treatment burden [Grošelj and Jan, 2013; da Costa Silva et al., 2017].

The treatment modalities recommended for $\mathrm{MIH}$-affected teeth vary widely depending on the severity of the defect and the presence of complicating factors, such as hypersensitivity, oral hygiene, and patient cooperation. The final treatment may also depend on the dentist's training and the availability/accessibility of care. Therefore, strategies ranging from implementation of preventive measures to rehabilitation, and even extraction, can be indicated [Elhennawy and Schwendicke, 2016]. In mild cases, when neither PEB nor cavitated caries lesions are present, the application of pit and fissure sealants can be indicated. Pit and fissure sealants have been proven to be effective in preventing caries in non-MIH molars [Ahovuo-Saloranta et al., 2017]. Comparing different sealant materials, it has been shown that resin-based sealants present a higher longevity (retention rates) compared to glass ionomer cement (GIC) sealants [Kühnisch et al., 2012]; but no difference was reported regarding their caries-preventive effect [Beiruti et al., 2006]. In fact, Mickenautsch and Yengopal [2016] showed that caries incidences between molars sealed with high-viscosity GIC or with resin-based sealants were similar.

When it comes to MIH-affected molars, little is known regarding the preventive effect of pit and fissure sealants, and contradictory results are found in the literature. While a retrospective study showed that fillings and sealants placed in MIH-affected molars had over 3 times greater probability of needing retreatment compared to the same interventions carried out on nonaffected molars [Kotsanos et al., 2005], another trial showed similar retention and secondary caries rates [Fragelli et al., 2017].

Although resin-based sealants are widely used in the prevention of caries in $\mathrm{MIH} /$ nonaffected molars [Fragel- li et al., 2017; Cvikl et al., 2018], it must be acknowledged that resin-based sealants require optimal conditions for placement, including excellent moisture control [Naaman et al., 2017]. Conversely, GIC sealants are easier for the operator to apply and less vulnerable to moisture [Cvikl et al., 2018], and therefore they are a suitable alternative when resin-based sealants cannot be used due to moisture control issues. Indeed, GIC sealants are frequently used in MIH molars when sealing is indicated even before the tooth has completely emerged into the mouth and ideal moisture control is not possible [Kopperud et al., 2016]. However, to date, no research has investigated the preventive effect of GIC sealants applied on $\mathrm{MIH}$-affected molars. Therefore, the aim of the present study was to evaluate the preventive effect of GIC sealants versus no sealant with regards to $\mathrm{PEB}$ and dental caries on MIH-affected molars after a 12-month follow-up period.

\section{Materials and Methods}

\section{Study Design and Sample Size Calculation}

This is a 2-arm, parallel-group, superiority trial that started in November 2018 and is planned to have a follow-up of 3 years. In this paper, we report the results after a 1-year follow-up. Participants were allocated to 1 of the 2 arms in order to compare the preventive effect of a GIC sealant (intervention group) versus no sealant (control group) on MIH-affected molars.

The sample size calculation was based on the primary outcome, i.e., the occurrence of PEB on MIH-affected molars of $29 \%$ after 1 year, as reported by Neves et al. [2019]. A minimum difference of $20 \%$ between the test and control groups was considered, and a power of $80 \%$ and a level of significance of $5 \%$ were adopted. Additionally, the sample size was increased to $40 \%$ to compensate for the design of this study (cluster per child), as more than 1 tooth could be included per child. Additionally, the final sample was increased to $20 \%$ to compensate for participant loss to follow-up. As a result, a minimum of $195 \mathrm{MIH}$-affected molars were required.

\section{Eligibility Criteria}

At baseline children were evaluated by 1 trained and calibrated pediatric dentist, with the same dentist performing the follow-up exams afterwards. The presence of $\mathrm{MIH}$ was evaluated according to the criteria proposed by Ghanim et al. [2017] and dental caries was evaluated according to International Caries Detection and Assessment System (ICDAS) criteria [Ismail et al., 2007]. The inclusion criteria were: children enrolled in elementary schools in Tepatitlán de Morelos (Jalisco, Mexico), aged between 5 and 9 years, with cooperative behavior, presenting at least $1 \mathrm{MIH}$-affected molar with at least a two-thirds erupted crown. The exclusion criteria were: children with ongoing orthodontic treatment, presenting dental fluorosis, amelogenesis, or dentinogenesis imperfecta, and children with syndromes or developmental disorders. Additionally, MIH-affected molars presenting opacities not located on the occlusal surfaces of the tooth, with clinically visible dentin caries 
lesions and/or any PEB, restorations, or sealants, and MIH-affected molars with the occlusal surface totally or partially covered by a gingival operculum, were excluded from this study.

The randomization unit was the child, so the included children had between 1 and $4 \mathrm{MIH}$-affected molars included in the present investigation. All of the included teeth from the same child were allocated to either the sealant group or the no-sealant group. The children were allocated to 1 of 2 groups using a randomization list generated by a website (http://www.randomization.com) using blocks of different sizes (4,6, and 8). Allocation concealment was guaranteed by the use of opaque envelopes, which were opened once the child was ready to receive an intervention.

\section{Treatment Procedure}

Sealants were applied by 2 final-year undergraduate dental students from the Academic Centre for Dentistry Amsterdam (ACTA) under direct supervision of experienced pediatric dentists. Before the start of this study, the operators followed training sessions, which comprised theoretical and practical laboratorybased workshops for handling and application of the GIC sealant used in this study. After that, the operators participated in a 2-week training in field settings with children who did not participate in this study.

Sealants were applied in a school setting according to the following clinical steps: (1) cotton roll wools were used to isolate the operative field, (2) dentin conditioner (GC Europe, Leuven, Belgium) was actively applied for $20 \mathrm{~s}$ on the occlusal surface, followed by rinsing with 3 wet cotton pellets and drying also with cotton pellets, (3) GIC capsule (Fuji Triage Pink; GC Europe) was mixed for $10 \mathrm{~s}$, (4) GIC was applied to the tooth using a capsule applier and it was further spread into the pits and fissures using a microbrush, (5) GIC was light cured for $30 \mathrm{~s}$ in order to speed up its setting, (6) occlusion was adjusted if necessary with the help of a manual excavator, and (7) a thin layer of GC Coat Plus (GC Europe) was applied with a microbrush and light cured for $20 \mathrm{~s}$.

Children in both groups received dietary advice and brushing instructions at baseline from a local dentist enrolled in the specialization course of pediatric dentistry at the University of Guadalajara. Brushing instructions included tooth brushing 3 times a day using a conventional toothbrush and toothpaste containing a fluoride concentration of $\geq 1,000 \mathrm{ppm}$. Furthermore, the patients were referred to the specialization course pediatric dentistry at the University of Guadalajara for those participants with additional dental needs.

\section{Training and Calibration}

One trained and calibrated pediatric dentist was responsible for the baseline examination and follow-up evaluations. The examiner underwent a theoretical training on MIH according to the criteria proposed by Ghanim et al. [2017]. This training consisted of $9 \mathrm{~h}$ of theoretical lectures, literature discussions, and evaluation of clinical pictures. A calibration exercise was performed by scoring clinical pictures of 40 patients. Additionally, the same evaluator followed a 30-h training program concerning dental caries detection according to ICDAS criteria [Ismail et al., 2007]. This training program was comprised of a theoretical explanation and discussions using clinical pictures. Thereafter, the evaluator conducted examinations in extracted teeth, as well as in 15 patients not participating in this study. Interexaminer agreement was calculated by comparing the scores given by the examiner and a "gold- standard" examiner. After 1 week, the evaluator repeated the same evaluations again for both $\mathrm{MIH}$ and dental caries outcomes in order to determine the intra-agreement calculations. $\kappa$ coefficient values for MIH were 0.77 for interexaminer and 0.95 for intraexaminer reliability. For dental caries, $\kappa$ values of 0.81 for interexaminer and 0.92 for intraexaminer reliability were achieved.

\section{Evaluation and Clinical Follow-Up}

Clinical evaluations were performed in school settings at baseline and after 6 and 12 months. Clinical exams were performed with the aid of a dental mirror, a periodontal probe, and an artificial light placed on the examiner's forehead. Cotton wool rolls were used for moisture control. Furthermore, a portable dental unit (Robotin 1 HP; Remac Dent, Mexico City, Mexico) was used to dry the teeth. Before each evaluation and sealant placement, the dental surfaces were professionally cleaned using the same portable dental unit and a Robinson brush at a low speed. The only exception was the evaluation of the oral hygiene profile of the participants, which was performed prior to teeth cleaning.

The primary outcome (PEB) was scored according to the criteria proposed by Ghanim et al. [2017]. Each molar was given one of the following scores: 0 , no visible enamel defect; 1 , enamel defect, not MIH/HSPM; 2, demarcated opacities; 3, PEB; 4, atypical restoration; 5, atypical caries; 6, missing due to MIH/HSPM; or 7, cannot be scored. A score of 7 was only used for teeth with extensive coronal breakdown where the potential cause of breakdown was impossible to determine. In cases where more than 1 score could be given to the same tooth, the highest one was recorded. For scores $2-6$, the extension of the lesion was classified using the following scores: A, less than one third of the tooth is affected; $\mathrm{B}$, at least one third but less than two thirds of tooth are affected; and C, at least two thirds of the tooth are affected. Demarcated opacities were classified according to their color as white-creamy or yellowbrown.

Dental caries was evaluated according to ICDAS criteria [Ismail et al., 2007] and given one of the following scores: 0, sound surface; A, initial stage caries (first visual change in enamel); B, moderate stage caries (localized enamel breakdown or underlying dark shadow); or $\mathrm{C}$, extensive stage caries (visible cavitation in dentin).

Sealant retention was evaluated according to the scoring system proposed by Oba et al. [2009]. One of the following scores was given: 0 , fully retained sealant; 1 , partially retained sealant, or 2, absent sealant. The oral hygiene profile of the participants was assessed at the baseline evaluation using the Debris Index (DI) of the Simplified Oral Hygiene Index (OHI-S) proposed by Greene and Vermillion [1964]. Patient-related characteristics, such as age (in years), sex (male or female), and distribution of the affected teeth by jaw (upper/lower), were also collected.

\section{Statistical Analysis}

Data were tabulated and analyzed using Stata statistical software (release 13; Stata Corp., College Station, TX, USA).

For the outcome PEB, a score of 2 indicated success and scores 3-6 indicated failure. For the outcome dental caries, scores A and $\mathrm{B}$ indicated success while score $\mathrm{C}$ indicated failure. For the outcome of sealant retention, scores 0 and 1 indicated success, while a score of 2 indicated failure.

Clustered logistic regression analysis (children) was used to determine the association between the outcomes PEB and dental car- 
Fig. 1. CONSORT flowchart for the progress of participants in the trial.

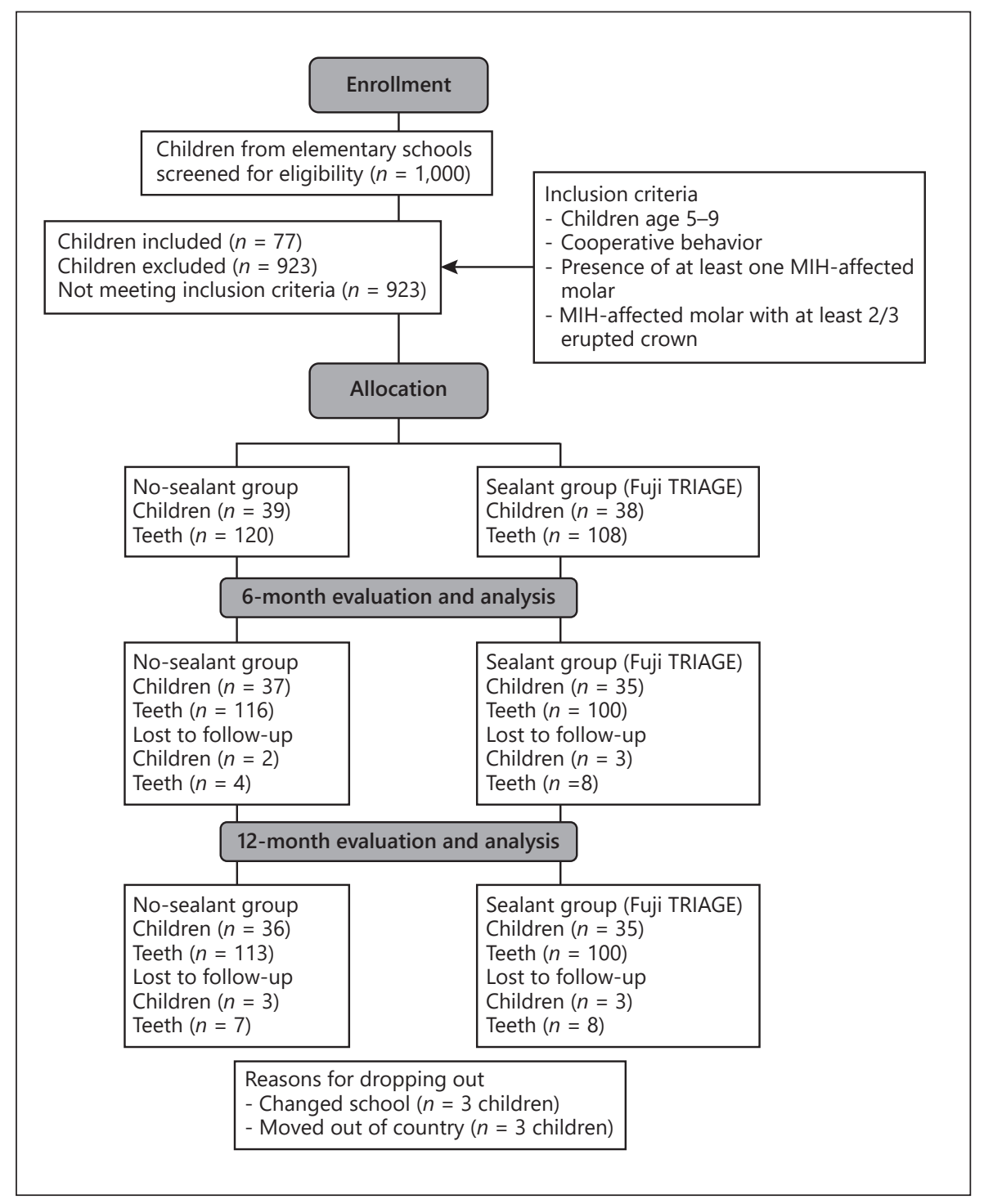

ies of MIH-affected molars with independent variables. First, a univariate logistic regression analysis was performed and all independent variables that reached a $p$ value $<0.20$ were used in the adjusted analysis. Kaplan-Meier survival analysis and Cox regression analysis were used for the subgroup analysis (sealant group) to investigate the association between sealant retention and independent variables. A power analysis for this last subgroup analysis was performed. The statistical significance level was set at $5 \%$ for all analyses.

\section{Results}

A total of 77 children and 228 molars were included in this study (Fig. 1). The sample comprised 40 (51.95\%) boys and 37 (48.05\%) girls. At baseline, the mean age was
6.81 years ( $\mathrm{SD}=0.87$, range $5-9$ years). A total of 34 children had $4 \mathrm{MIH}$-affected molars were included in this research; 15 children had 3, 19 children had 2, and 9 children had only $1 \mathrm{MIH}$-affected molar included. Baseline characteristics such as sex, age, distribution of teeth by upper/lower jaw, color of opacities, extension of lesions, and oral hygiene at baseline were equally distributed between the sealant and no-sealant groups (Table 1). At baseline, a total of 14 teeth were not classified regarding the color of the opacity and 18 had missing data regarding the presence of (initial) dental caries. A total of 143 teeth had initial caries lesions at baseline (68.1\% of the sample), with no differences between the groups.

After 12 months, 71 children and 213 molars were reassessed (dropout rate: 7.8\%). From those, 113 molars 
Table 1. Descriptive statistics for the sealant and no-sealant groups at baseline

\begin{tabular}{|c|c|c|c|c|}
\hline Variable & Sealant & No sealant & Total, $n$ & $p$ value \\
\hline \multicolumn{5}{|l|}{ Gender } \\
\hline Male & $58(50.43)$ & $57(49.57)$ & 115 & \multirow[t]{2}{*}{$0.450^{\mathrm{a}}$} \\
\hline Female & $62(54.87)$ & $51(45.13)$ & 113 & \\
\hline Age, years & $6.71 \pm 0.79$ & $6.75 \pm 0.92$ & $6.73 \pm 0.85$ & $0.653^{\mathrm{b}}$ \\
\hline \multicolumn{5}{|l|}{ Tooth } \\
\hline Upper & $53(53.54)$ & $46(46.46)$ & 99 & \multirow[t]{2}{*}{$0.057^{\mathrm{a}}$} \\
\hline Lower & $67(51.94)$ & $62(48.06)$ & 129 & \\
\hline \multicolumn{5}{|c|}{ Color at baseline (missing data: $n=14$ teeth) } \\
\hline White-creamy & $76(49.35)$ & $78(50.65)$ & 154 & \multirow[t]{2}{*}{$2.282^{\mathrm{a}}$} \\
\hline Yellow-brown & $35(58.33)$ & $25(41.67)$ & 60 & \\
\hline \multicolumn{5}{|c|}{ Extension of the hypomineralisation defect baseline } \\
\hline Less than one third affected (reference) & $39(53.42)$ & $34(46.58)$ & 73 & \multirow[t]{3}{*}{$1.664^{\mathrm{a}}$} \\
\hline One third to two thirds affected & $52(57.78)$ & $38(42.22)$ & 90 & \\
\hline More than two thirds affected & $29(44.62)$ & $36(55.38)$ & 65 & \\
\hline \multicolumn{5}{|c|}{ Dental caries at baseline (missing data: $n=18$ ) } \\
\hline No caries (ICDAS 0) & $41(61.19)$ & $26(38.81)$ & 67 & \multirow[t]{2}{*}{$0.098^{\mathrm{a}}$} \\
\hline Initial caries (ICDAS 1/2) & $70(48.95)$ & $73(51.05)$ & 143 & \\
\hline Oral health index at baseline & $1.64 \pm 0.31$ & $1.64 \pm 0.43$ & $1.64 \pm 0.37$ & $0.868^{\mathrm{b}}$ \\
\hline
\end{tabular}

Values are presented as numbers (\%) or means \pm SD. ${ }^{a} \chi^{2}$ test. ${ }^{b}$ Two-sample $t$ test.

Table 2. Association between the presence of a posteruptive breakdown of MIH-affected molars and independent variables using a clustered logistic regression analysis

\begin{tabular}{|c|c|c|c|c|c|c|c|}
\hline Variable & No PEB & PEB & $\begin{array}{l}\text { Total, } \\
n\end{array}$ & $\begin{array}{l}\text { Univariate OR } \\
(95 \% \mathrm{CI})\end{array}$ & $\begin{array}{l}p \\
\text { value }\end{array}$ & $\begin{array}{l}\text { Adjusted OR } \\
(95 \% \mathrm{CI})\end{array}$ & $\begin{array}{l}p \\
\text { value }\end{array}$ \\
\hline \multicolumn{8}{|l|}{ Group } \\
\hline No sealant (reference) & $100(88.50)$ & $13(11.50)$ & 113 & $0.57(0.20-1.67)$ & 0.313 & - & - \\
\hline Sealant & $93(93.00)$ & $7(7.00)$ & 100 & & & & \\
\hline \multicolumn{8}{|l|}{ Tooth } \\
\hline Upper (reference) & $84(88.42)$ & $11(11.58)$ & 95 & $0.63(0.22-1.85)$ & 0.400 & - & - \\
\hline Lower & $109(92.37)$ & $9(7.63)$ & 118 & & & & \\
\hline \multicolumn{8}{|c|}{ Color baseline (missing data: $n=14$ teeth) } \\
\hline White-creamy (reference) & $138(95.17)$ & $7(4.83)$ & 145 & $5.04(1.85-13.74)$ & $0.002^{\mathrm{a}}$ & $5.80(2.00-16.79)$ & $0.001^{\mathrm{a}}$ \\
\hline Yellow-brown & $43(79.63)$ & $11(20.37)$ & 54 & & & & \\
\hline \multicolumn{8}{|c|}{ Extension of the hypomineralization defect at baseline } \\
\hline $\begin{array}{l}\text { Less than one third } \\
\text { affected (reference) }\end{array}$ & $62(93.94)$ & $4(6.06)$ & 66 & $2.97(0.94-9.43)$ & 0.063 & $1.80(0.54-6.05)$ & 0.336 \\
\hline $\begin{array}{l}\text { One third to two thirds } \\
\text { affected }\end{array}$ & $73(83.91)$ & $14(16.09)$ & 87 & & & & \\
\hline $\begin{array}{l}\text { More than two thirds } \\
\text { affected }\end{array}$ & $58(96.67)$ & $2(3.33)$ & 60 & $0.53(0.10-2.95)$ & 0.472 & $0.28(0.03-2.29)$ & 0.236 \\
\hline \multicolumn{8}{|c|}{ Dental caries at baseline (missing data: $n=18$ teeth) } \\
\hline No caries (reference) & $174(90.63)$ & $18(9.37)$ & 192 & $1.84(0.58-5.80)$ & 0.298 & - & - \\
\hline Initial caries & $3(100.00)$ & $0(0.00)$ & 3 & & & & \\
\hline Oral health index at baseline & $1.64 \pm 0.38$ & $1.62 \pm 0.35$ & $\begin{array}{l}1.64 \\
(0.37)\end{array}$ & $0.84(0.20-3.59)$ & 0.812 & - & - \\
\hline Total & $193(90.15)$ & $20(9.85)$ & 213 & & & & \\
\hline
\end{tabular}

Analysis adjusted by age and gender. Values are presented as numbers (\%) or means \pm SD unless otherwise stated. ${ }^{\text {a }}$ Statistically significant difference. 
Table 3. Association between dental caries and independent variables using clustered logistic regression analysis

\begin{tabular}{|c|c|c|c|c|c|c|c|}
\hline Variable & No caries & Caries & Total, $n$ & $\begin{array}{l}\text { Univariate OR } \\
(95 \% \mathrm{CI})\end{array}$ & $p$ value & $\begin{array}{l}\text { Adjusted OR } \\
(95 \% \mathrm{CI})\end{array}$ & $p$ value \\
\hline \multicolumn{8}{|l|}{ Group } \\
\hline Sealant & $96(96.00)$ & $4(4.00)$ & 100 & & & & \\
\hline \multicolumn{8}{|l|}{ Tooth } \\
\hline Upper (reference) & $89(93.68)$ & $6(6.32)$ & 95 & $1.52(0.53-4.40)$ & 0.435 & - & - \\
\hline \multicolumn{8}{|c|}{ Color at baseline (missing data: $n=14$ teeth) } \\
\hline White-creamy (reference) & $140(96.55)$ & $5(3.45)$ & 145 & $6.36(1.86-21.80)$ & $0.003^{\mathrm{a}}$ & $4.95(1.40-17.54)$ & $0.013^{\mathrm{a}}$ \\
\hline Yellow-brown & $44(81.48)$ & $10(18.52)$ & 54 & & & & \\
\hline \multicolumn{8}{|c|}{ Extension of the hypomineralization defect at baseline } \\
\hline $\begin{array}{l}\text { Less than one third affected } \\
\text { (reference) }\end{array}$ & $63(95.45)$ & $3(4.55)$ & 66 & $2.72(0.64-11.68)$ & 0.176 & - & - \\
\hline Initial caries & $3(100.00)$ & $0(0.00)$ & 3 & & & & \\
\hline Oral health index at baseline & $1.62 \pm 0.35$ & $1.80 \pm 0.54$ & $1.63 \pm 0.37$ & $3.67(0.27-49.84)$ & 0.328 & - & - \\
\hline Total & $196(92.02)$ & $17(7.98)$ & 213 & & & & \\
\hline
\end{tabular}

Analysis adjusted by age and gender. Values are presented as numbers (\%) or means \pm SD unless otherwise stated. ${ }^{a}$ Statistically significant difference.

(53.1\%) were in the no-sealant group and $100(46.9 \%)$ were in the sealant group. Regarding the color of the opacity, $68.1 \%$ were white-creamy while $25.4 \%$ were yellow-brown.

The results of the clustered logistic regression analysis of the association between the presence of PEB and patient-related variables is displayed in Table 2. The results showed that the application of a GIC sealant did not protect molars against $\mathrm{PEB}$, atypical restoration, atypical caries, or extraction due to MIH ( $p=0.313)$. However, a significant association was observed regarding PEB and the color of the opacities, as teeth with yellow-brown opacities were 5 times more likely to have PEB, atypical restoration, atypical caries, or extraction due to MIH after a 1 -year follow-up $(\mathrm{OR}=5.80 ; 95 \%$ CI 2.0-16.0; $p=$ $0.001)$.

The results of the clustered logistic regression for the association between dental caries and patient-related variables is depicted in Table 3 and demonstrated that sealed molars presented $77 \%$ less of a chance of caries progression compared to the no-sealant group ( $\mathrm{OR}=$ 0.23 ; 95\% CI $0.06-0.95 ; p=0.042$ ). Also, yellow-brown opacities were almost 5 times more likely to show signs of caries progression compared to white-creamy opacities $(\mathrm{OR}=4.95 ; 95 \%$ CI $1.40-17.54 ; p=0.013)$.
In relation to the subgroup analysis for sealant retention ( $n=100)$, the survival rate of fully and partially retained GIC sealants was 91 and $83 \%$ after 6 and 12 months, respectively. Table 4 depicts the results of the Cox logistic regression for the subgroup analysis, in which no association between variables and sealant retention was found (power analysis $=78.2 \%$ ). A $\chi^{2}$ test for sealant group did not reveal any significant association between sealant retention and caries progression $(p=0.663)$ or PEB $(p=0.746)$.

\section{Discussion}

This is the first study to evaluate the preventive effect of GIC sealants applied in field conditions on the outcomes PEB and dental caries in MIH-affected molars. The results showed that molars that were not sealed were $77 \%$ more likely to develop dental caries compared to molars that received a GIC sealant application. This caries-preventive effect of GIC sealants has already been observed in previous investigations carried out on molars not affected by MIH [Yengopal et al., 2009; Mickenautsch and Yengopal, 2011; Cabral et al., 2018]. One of the factors that can explain this protective effect is that the material applied on occlusal surfaces acts as a mechanical bar- 
Table 4. Subgroup analysis: association between sealant retention after 12 months and independent variables using a clustered Cox regression analysis

\begin{tabular}{|c|c|c|c|c|}
\hline Variable & $\begin{array}{l}\text { Sealant } \\
\text { survival, \% }\end{array}$ & SE & $\begin{array}{l}\text { Univariate HR } \\
(95 \% \mathrm{CI})\end{array}$ & $p$ value \\
\hline \multicolumn{5}{|l|}{ Gender } \\
\hline Male (reference) & 85.11 & 0.05 & $1.22(0.39-3.83)$ & 0.732 \\
\hline Female & 81.13 & 0.05 & & \\
\hline Age, years & 83.00 & 0.03 & $0.75(0.40-1.40)$ & 0.363 \\
\hline \multicolumn{5}{|l|}{ Tooth } \\
\hline Upper (reference) & 81.82 & 0.06 & $0.86(0.38-1.96)$ & 0.728 \\
\hline Lower & 83.93 & 0.05 & & \\
\hline \multicolumn{5}{|l|}{ Color baseline } \\
\hline White-creamy (reference) & 82.43 & 0.03 & $1.22(0.42-3.53)$ & 0.711 \\
\hline Yellow-brown & 80.00 & 0.09 & & \\
\hline \multicolumn{5}{|c|}{ Extension of the hypomineralization defect at baseline } \\
\hline $\begin{array}{l}\text { Less than one third affected } \\
\text { (reference) }\end{array}$ & 83.87 & 0.07 & & \\
\hline One third to two thirds affected & 83.78 & 0.06 & $1.04(0.39-2.82)$ & 0.934 \\
\hline More than two thirds affected & 81.25 & 0.07 & $1.16(0.28-4.90)$ & 0.839 \\
\hline \multicolumn{5}{|l|}{ Caries at baseline } \\
\hline No caries (reference) & 84.85 & 0.06 & $1.18(0.47-2.98)$ & 0.724 \\
\hline Initial caries & 82.09 & 0.05 & & \\
\hline Total & 83.00 & 0.03 & & \\
\hline
\end{tabular}

rier, physically isolating the pits and fissures from the oral environment [Muller-Bolla et al., 2006]. Additionally, one of the main advantages of GIC is fluoride release, which is associated with both caries prevention and arrestment [Bayrak et al., 2010; Mickenautsch et al., 2011]. In the case of MIH-affected molars, it has also been argued that sealant application helps to decrease hypersensitivity [Elhennawy and Schwendicke, 2016], enabling better plaque removal by the patient and therefore contributing to caries prevention.

This preventive effect was not observed for the outcome PEB, as no statistically significant difference was observed between MIH-affected molars that were sealed and those that remained unsealed ( $p=0.313)$. It has been suggested that application of a GIC sealant can protect MIH-affected molars against PEB [Lygidakis, 2010] and the most accepted theory is that the fluoride present in this material may diffuse into the affected enamel and dentin, enhancing mineralization of the hypomineralized areas [Lygidakis, 2010]. A previous study proved this effect on enamel not affected by MIH [Kucukyilmaz and Savas, 2016]. We hypothesize that fluoride released from GIC can somehow improve the hardness of MIH-affected dental substrates; however, the results of our study suggest that this enhancement is not enough to prevent the occurrence of PEB.

Preventive Effect of GIC Sealants on MIH-Affected Molars
In the present study, MIH-affected molars with yellow-brown colored opacities were more likely to develop dental caries and PEB than MIH-affected molars with white-creamy colored opacities. These results are in line with previous investigations [Da Costa-Silva et al., 2011; Neves et al., 2019] that reported more PEB after 12 months of evaluation on yellow-brown opacities. This is likely to be related to the fact that yellow-brown opacities are more porous and less mineralized than the white-creamy ones [Jälevik and Norén, 2000], which may be a risk factor for PEB [Da Costa-Silva et al., 2011].

This study suggests an association between the presence of dentin caries lesions and PEB. Although PEB had occurred in only $20 \mathrm{MIH}$-affected molars after 12 months, more than $50 \%$ of those molars (11 molars) showed dentine caries as well. MIH-affected molars are more prone to $\mathrm{PEB}$ as a result of a decreased phosphorus and calcium content in the enamel [Weerheijm et al., 2001; Weerheijm, 2003; Grošelj and Jan, 2013]; clinically, this can be translated to a more brittle enamel, which tends to break when submitted to masticatory forces [Weerheijm et al., 2001]. Once surface loss due to PEB has occurred, and the clinical stage of MIH has become more severe, plaque removal becomes difficult for the patient [Ebel et al., 2018]. However, it is not well established whether PEB leads to caries development or if dental caries is a contributing 
factor to PEB. This area requires further exploration before a definitive conclusion can be drawn.

In this study, a cumulative survival rate of $83 \%$ for fully and partially retained sealants was determined after a period of 12 months, which is in line with previous studies using the same low-viscosity GIC when applied to molars not affected by MIH [Alsabek et al., 2019]. More importantly, this study found no association between sealant retention and dental caries or PEB. For dental caries, it has already been proven that sealant retention is not the most important parameter to be considered since, especially for GIC sealants, failures in retention cannot be considered a predictor for caries progression in permanent molars [Mickenautsch and Yengopal, 2013].

Along with its strengths, this study also has limitations. Blinding of the operators and the evaluator was not possible due to the nature of the interventions. Moreover, the short follow-up period could be considered a limitation. However, we plan to follow up these children for a period of 3 years. Another point of discussion is the detection of dental caries, as this study was carried out in field conditions, where the detection of initial- and moderatestage caries lesions can be problematic. In order to overcome this possible drawback, only extensive caries (ICDAS/ICCMS score C) was considered as a failure for the outcome dental caries, most probably leading to underestimation of the disease. Therefore, we carried out the statistical analysis considering both moderate (ICDAS/ICCMS score B) and extensive lesions (ICDAS/ ICCMS score C) as a failure, resulting in the same associations being found in the analysis. Nevertheless, most studies regarding the caries-preventive effect of GIC sealants have used the ICDAS/ICCMS score $\mathrm{C}$ as the caries cutoff point and, therefore it was deemed appropriate in terms of comparability to use the ICDAS/ICCMS score C as indicative of failure for the outcome dental caries in our trial. [Hilgert et al., 2015; de Amorim et al., 2018].

The choice of Fuji Triage (GC Europe) as the GIC for the sealants applied in this study was based on this material's characteristics. Its low viscosity may increase the penetration of the material into the porosities of the hypomineralized enamel, and the pink color facilitates evaluation of the sealant during clinical exams. Additionally, this material can release 7-10 times more fluoride than the reinforced conventional GIC [Mast et al., 2013], possibly enhancing the preventive effect of this material when applied to MIH-affected enamel. These characteristics may result in this type of GIC being a suitable material for the sealing of $\mathrm{MIH}$-affected molars, even when better results with the use of high-viscosity GIC in teeth not affected by MIH have been reported [Frencken et al., 2004]. Therefore, more research into these different types of GIC is required in order to guide the material choice in MIH-affected teeth.

The present study allows us to conclude that application of a GIC sealant on MIH-affected molars was effective in the prevention of dentin caries lesions after a follow-up period of 12 months. Conversely, this preventive effect was not observed for the prevention of PEB on those molars.

\section{Acknowledgement}

We would like to thank the schoolchildren, their parents, and the staff of the schools for their kind assistance in the conduction of this study. We are very grateful to Tina Mounessiani and Hiwa Mohajer Soltani for their dedication during the operative phase of this study. We would like to express our gratitude to GC Europe for kindly donating the materials used in this study and to Dr. Kirsten Fitzgerald and Charlotte McCarra for kindly reviewing the English language of this paper.

\section{Statement of Ethics}

This study followed the guidelines published by the Consolidated Standards of Reporting Trials [Schulz et al., 2010]. Ethical clearance to conduct this study was obtained from the Research Ethics Committee of the University of Guadalajara (protocol CUA/CEI/100/2018), and the study protocol is registered on ClinicalTrials.gov (NCT03870958). The children and their parents or legal guardians provided signed informed consent prior the start of this investigation.

\section{Conflict of Interest Statement}

The manufactures had no role in the study design, data collection and analysis, the decision to publish, or the preparation of this. The authors declare no conflict of interests.

\section{Funding Sources}

No funding sources contributed to this research.

\section{Author Contributions}

I.C.O., C.C.B., and D.H. conceived the ideas. M.S.S., A.P.R.G., and M.P. collected the data. I.C.O. and D.H. performed the statistical analysis and critical evaluation. All of the authors were involved in the writing of this paper and read and approved the final version of this work. 


\section{References}

Ahovuo-Saloranta A, Forss H, Walsh T, Nordblad A, Mäkelä M, Worthington H V.: Pit and fissure sealants for preventing dental decay in permanent teeth. Cochrane Database Syst Rev. 2017 Jul;7(7):CD001830.

Alsabek L, Al-Nerabieah Z, Bshara N, Comisi JC. Retention and remineralization effect of moisture tolerant resin-based sealant and glass ionomer sealant on non-cavitated pit and fissure caries: randomized controlled clinical trial. J Dent. 2019 Jul;86:69-74.

Bayrak S, Tunc ES, Aksoy A, Ertas E, Guvenc D, Ozer S. Fluoride release and recharge from different materials used as fissure sealants. Eur J Dent. 2010 Jul;4(3):245-50.

Beiruti N, Frencken JE, van 't Hof MA, van Palenstein Helderman WH. Caries-preventive effect of resin-based and glass ionomer sealants over time: a systematic review. Community Dent Oral Epidemiol. 2006 Dec;34(6):403-9.

Cabral RN, Faber J, Otero SA, Hilgert LA, Leal SC. Retention rates and caries-preventive effects of two different sealant materials: a randomised clinical trial. Clin Oral Investig. 2018 Dec;22(9):3171-7.

Cvikl B, Moritz A, Bekes K. Pit and fissure sealants-A comprehensive review. Dent J (Basel). 2018 Jun;6(2):18.

Da Costa-Silva CM, Ambrosano GM, Jeremias F, De Souza JF, Mialhe FL. Increase in severity of molar-incisor hypomineralization and its relationship with the colour of enamel opacity: a prospective cohort study. Int J Paediatr Dent. 2011 Sep;21(5):333-41.

da Costa Silva CM, Ortega EM, Mialhe FL. The Impact of Molar-Incisor Hypomineralisation on Dental Caries in Permanent First Molars: A Prospective Cohort Study. Oral Health Prev Dent. 2017;15(6):581-6.

Dave M, Taylor G. Global prevalence of molar incisor hypomineralisation. Evid Based Dent. 2018 Oct;19(3):78-9.

de Amorim RG, Frencken JE, Raggio DP, Chen X, $\mathrm{Hu} \mathrm{X}$, Leal SC. Survival percentages of atraumatic restorative treatment (ART) restorations and sealants in posterior teeth: an updated systematic review and meta-analysis. Clin Oral Investig. 2018 Nov;22(8):2703-25.

Ebel M, Bekes K, Klode C, Hirsch C. The severity and degree of hypomineralisation in teeth and its influence on oral hygiene and caries prevalence in children. Int J Paediatr Dent. 2018 Nov;28(6):648-57.

Elhennawy K, Schwendicke F. Managing molarincisor hypomineralization: A systematic review. J Dent. 2016 Dec;55:16-24.

Fagrell TG, Dietz W, Jälevik B, Norén JG. Chemical, mechanical and morphological properties of hypomineralized enamel of permanent first molars. Acta Odontol Scand. 2010 Jul;68(4):215-22.

Farah R, Drummond B, Swain M, Williams S. Linking the clinical presentation of molar-incisor hypomineralisation to its mineral density. Int $J$ Paediatr Dent. 2010 Sep;20(5):353-60.
Fragelli CM, Souza JF, Bussaneli DG, Jeremias F, Santos-Pinto LD, Cordeiro RC. Survival of sealants in molars affected by molar-incisor hypomineralization: 18-month follow-up. Braz Oral Res. 2017 Apr;31(0):e30.

Frencken JE, Van 't Hof MA, Van Amerongen WE, Holmgren CJ. Effectiveness of singlesurface ART restorations in the permanent dentition: a meta-analysis. J Dent Res. 2004 Feb;83(2):120-3.

Ghanim A, Silva MJ, Elfrink ME, Lygidakis NA, Mariño RJ, Weerheijm KL, et al. Molar incisor hypomineralisation $(\mathrm{MIH})$ training manual for clinical field surveys and practice. Eur Arch Paediatr Dent. 2017 Aug;18(4):225-42.

Greene JC, Vermillion JR. The Simplified Oral Hygiene Index. J Am Dent Assoc. 1964 Jan;68(1):7-13.

Grošelj M, Jan J. Molar incisor hypomineralisation and dental caries among children in Slovenia. Eur J Paediatr Dent. 2013 Sep;14(3): 241-5.

Gurrusquieta BJ, Núñez VM, López ML. Prevalence of molar incisor hypomineralization in Mexican children. J Clin Pediatr Dent. 2017;41(1):18-21.

Hilgert LA, Leal SC, Mulder J, Creugers NH, Frencken JE. Caries-preventive Effect of Supervised Toothbrushing and Sealants. J Dent Res. 2015 Sep;94(9):1218-24.

Ismail AI, Sohn W, Tellez M, Amaya A, Sen A, Hasson $\mathrm{H}$, et al. The International Caries Detection and Assessment System (ICDAS): an integrated system for measuring dental caries. Community Dent Oral Epidemiol. 2007 Jun;35(3):170-8.

Jälevik B, Norén JG. Enamel hypomineralization of permanent first molars: a morphological study and survey of possible aetiological factors. Int J Paediatr Dent. 2000 Dec;10(4):27889.

Kopperud SE, Pedersen CG, Espelid I. Treatment decisions on Molar-Incisor Hypomineralization (MIH) by Norwegian dentists - a questionnaire study. BMC Oral Health. 2016 Jul;17(1):3.

Kotsanos N, Kaklamanos EG, Arapostathis K. Treatment management of first permanent molars in children with Molar-Incisor Hypomineralisation. Eur J Paediatr Dent. 2005 Dec;6(4):179-84.

Kucukyilmaz E, Savas S. Evaluation of shear bond strength, penetration ability, microleakage and remineralisation capacity of glass ionomer-based fissure sealants. Eur J Paediatr Dent. 2016 Mar;17(1):17-23.

Kühnisch J, Mansmann U, Heinrich-Weltzien R, Hickel R. Longevity of materials for pit and fissure sealing-results from a meta-analysis. Dent Mater. 2012 Mar;28(3):298-303.

Lygidakis NA. Treatment modalities in children with teeth affected by molar-incisor enamel hypomineralisation (MIH): A systematic review. Eur Arch Paediatr Dent. 2010 Apr;11(2):65-74.
Mast P, Rodrigueztapia MT, Daeniker L, Krejci I. Understanding MIH: definition, epidemiology, differential diagnosis and new treatment guidelines. Eur J Paediatr Dent. 2013 Sep;14(3):204-8.

Mickenautsch S, Mount G, Yengopal V. Therapeutic effect of glass-ionomers: an overview of evidence. Aust Dent J. 2011 Mar;56(1):10-5.

Mickenautsch S, Yengopal V. Caries-preventive effect of glass ionomer and resin-based fissure sealants on permanent teeth: an update of systematic review evidence. BMC Res Notes. 2011 Jan;4(1):22.

Mickenautsch S, Yengopal V. Retention loss of resin based fissure sealants - a valid predictor for clinical outcome? Open Dent J. 2013 Aug;7(1):102-8.

Mickenautsch S, Yengopal V. Caries-preventive effect of high-viscosity glass ionomer and resin-based fissure sealants on permanent teeth: A systematic review of clinical trials. PLoS One. 2016 Jan;11(1):e0146512.

Muller-Bolla M, Lupi-Pégurier L, Tardieu C, Velly AM, Antomarchi C. Retention of resinbased pit and fissure sealants: A systematic review. Community Dent Oral Epidemiol. 2006 Oct;34(5):321-36.

Naaman R, El-Housseiny AA, Alamoudi N. The Use of Pit and Fissure Sealants-A Literature Review. Dent J (Basel). 2017 Dec;5(4):34.

Neves AB, Americano GC, Soares DV, Soviero VM. Breakdown of demarcated opacities related to molar-incisor hypomineralization: a longitudinal study. Clin Oral Investig. 2019 Feb;23(2):611-5.

Oba AA, Dülgergil T, Sönmez IŞ, Doğan S. Comparison of caries prevention with glass ionomer and composite resin fissure sealants. J Formos Med Assoc. 2009 Nov;108(11):844-8.

Schulz KF, Altman DG, Moher D; CONSORT Group. CONSORT 2010 statement: updated guidelines for reporting parallel group randomised trials. BMJ. 2010 Mar;340:c332.

Schwendicke F, Elhennawy K, Reda S, Bekes K, Manton DJ, Krois J. Global burden of molar incisor hypomineralization. J Dent. 2018 Jan;68:10-8.

Weerheijm KL. Molar Incisor Hypomineralisation (MIH). Eur J Paediatr Dent. 2003;4:11520.

Weerheijm KL, Jälevik B, Alaluusua S. Molar-incisor hypomineralisation. Caries Res. 2001 Sep-Oct;35(5):390-1.

Yengopal V, Mickenautsch S, Bezerra AC, Leal SC. Caries-preventive effect of glass ionomer and resin-based fissure sealants on permanent teeth: a meta analysis. J Oral Sci. 2009 Sep;51(3):373-82.

Zhao D, Dong B, Yu D, Ren Q, Sun Y. The prevalence of molar incisor hypomineralization: evidence from 70 studies. Int J Paediatr Dent. 2018 Mar;28(2):170-9. 